Article

\title{
Systematic and Model-Assisted Process Design for the Extraction and Purification of Artemisinin from Artemisia annua L.-Part I: Conceptual Process Design and Cost Estimation
}

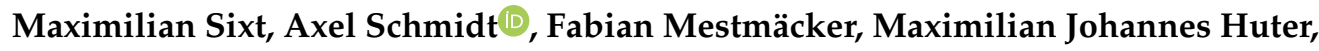 \\ Lukas Uhlenbrock and Jochen Strube * \\ Institute for Separation and Process Technology, Clausthal University of Technology, 38678 Clausthal-Zellerfeld, \\ Germany; sixt@itv.tu-clausthal.de (M.S.); schmidt@itv.tu-clausthal.de (A.S.); \\ mestmaecker@itv.tu-clausthal.de (F.M.); huter@itv.tu-clausthal.de (M.J.H.); uhlenbrock@itv.tu-clausthal.de (L.U.) \\ * Correspondence: strube@itv.tu-clausthal.de; Tel.: +49-5323-72-2355
}

Received: 13 July 2018; Accepted: 3 September 2018; Published: 7 September 2018

check for updates

\begin{abstract}
The article summarizes a systematic process design for the extraction and purification of artemisinin from annual mugwort (Artemisia annua L.). Artemisinin serves as an anti-malaria drug, therefore, resource-efficient and economic processes for its production are needed. The process design was based on lab-scale experiments and afterwards piloted on miniplant-scale at the institute. In this part of the article, a detailed economic feasibility studies including a reference process as a benchmark the lab-scale process and the pilot-scale process is given. Relevant differences between the different scales are discussed. The details of the respective unit operations (solid-liquid extraction, liquid-liquid extraction, chromatography and crystallization) are presented in dedicated articles. The study showed that even miniaturized lab-scale experiments are able to deliver data detailed enough for scale-up calculations on a theoretical basis. To our knowledge, a comparable systematic process design and piloting was never performed by academia before.
\end{abstract}

Keywords: artemisinin; process design; cost estimation; piloting; miniplant

\section{Introduction}

The demand for natural derived products is still growing [1,2]. Among others, they are used as highly purified products derived from plant extracts for the treatment of various diseases. One example is the anti-cancer drug Paclitaxel ${ }^{\circledR}$ which is produced by semi-synthesis from the precursor 10-deacetylbaccatin III, that is found in the needles of European yew (Taxus baccata L.). Another substance is the anti-malaria agent artemisinin from annual mugwort (Artemisia annua L.). These substances are extracted from the plant matrix and afterwards purified to pharma grade, typically by liquid-liquid extraction, chromatography, and a final crystallization [3-6].

The whole study, containing a conceptual process design, cost estimation, and a detailed investigation of solid-liquid extraction, liquid-liquid extraction, chromatography, and crystallization, has been split into five articles, as follows:

Part 0: Sixt, M.; Strube, J. Systematic and model-assisted evaluation of solvent based- or pressurized hot water extraction for the extraction of Artemisinin from Artemisia annua L. Processes 2017, 5, 86, doi:10.3390/pr5040086.

Part I: Sixt, Schmidt et al. Conceptual process design and cost estimation (this article);

Part II: Schmidt, Sixt et al. Model-based design of agitated and packed columns for multistage extraction and scrubbing. Processes, Revised version review; 
Part III: Mestmäcker, Schmidt et al. Chromatographic purification. Processes, Pending editor decision; Part IV: Huter, Schmidt et al. Crystallization. Processes, Under review.

In a previous publication by the institute, a model based optimization for the extraction of artemisinin with either acetone as solvent or the use of pressurized hot water as a new process option in multi-unit operations was investigated and optimized [7]. In the present study, the systematic process design for purification of artemisinin from mugwort is shown. The concept was developed on the example of 10-deacetylbaccatin III from yew and is depicted in Figure 1 below [6].

- $\quad$ The first step is the solid-liquid extraction discussed in detail in [7].

- The extract is filtered and afterwards the organic solvent is partly recycled. In this step, the precipitation of chlorophyll commonly takes place due to the accumulation of water in the extract in which chlorophyll is not soluble. If this does not occur, chlorophyll can be precipitated by adding water as an anti-solvent.

- The thickened extract is filtered once again to separate the precipitate.

- A whole series of liquid-liquid extraction steps serves to further increase the target component's concentration whilst separating side components.

- In a final step, the pure component is obtained either by preparative chromatography or crystallization or rather by coupling these two steps.

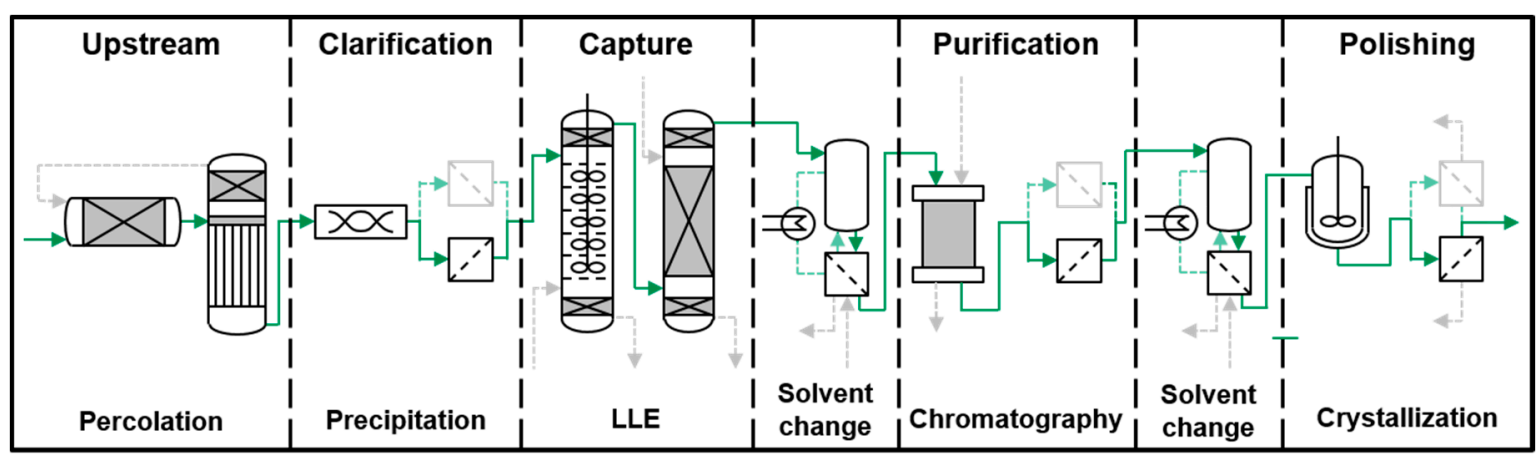

Figure 1. The basic process design for plant-based substances (LLE, liquid-liquid extraction).

Annual mugwort (Artemisia annua L.) from the Asteraceae family is an annual plant, growing mainly in moderate climatic and reaching heights of up to $2 \mathrm{~m}$. The main active ingredient in annual mugwort is the sesquiterpene lactone artemisinin, which amounts to around $0.01 \mathrm{wt} \%$ to $1.5 \mathrm{wt} \%$ of the plant [8]. Artemisinin is used to fight malaria, because of its efficacy against parasites of the species plasmodium $[9,10]$. It is mainly located in flowers and leave of the annual mugwort and stored in glandular trichomes on the surface of leaves, because of its toxicity for the plants cells [11]. This way artemisinin acts as natural protection against different natural enemies, e.g., predators, fungi or other pathogens [12].

The isolation of artemisinin was first achieved by Chinese scientist Tu Youyou and awarded with the 2015 Nobel Prize in Medicine together with William C. Campbell and Satoshi Ōmura [13].

The characteristic of the molecule, shown in Figure 2, is the peroxide bridge, believed to be responsible for the drug's mechanism of action [14].

A patent-based process serves as a benchmark for the further assessments [15,16]. The flow scheme is depicted in Figure 3.

An amount of 1000 t/a of dried mugwort (CfM Oskar Tropitzsch, Markredwitz, Germany) with an average artemisinin content of $0.395 \%$ [7] (according to the literature, $0.01-1.4 \%$ [8]) is first crushed and percolated with ethanol (VWR ${ }^{2}$, Darmstadt, Germany). The extract is concentrated by means of a falling-film evaporator with solvent recovery. In the next step, the concentrated extract is further concentrated by a liquid-liquid extraction and freed from part of the secondary components, 
with hexane $\left(\mathrm{VWR}^{\circledR}{ }^{\circledR}\right.$, Darmstadt, Germany) as the solvent. Subsequently, the artemisinin is purified by normal phase column chromatography with a hexane-ethyl acetate system (VWR®, Darmstadt, Germany). The volume of the artemisinin fraction from the chromatography is further concentrated in an evaporator (IKA®-Werke GmbH \& Co. KG, Staufen, Germany) and then the product is recovered by crystallization. The final step in the process is to dry the artemisinin. The overall process shows a loss of about $41 \%$, yielding $2935 \mathrm{~kg}$ of pure artemisinin per year, which is about $2 \%$ of the world demand. The investment costs amount to $€ 5.74$ million. Annual operating costs amount to $€ 8.4$ million, resulting in a production cost of $2.87 € / \mathrm{g}$ artemisinin. An Internet pharmacy offers 12 tablets of artemisinin, each $40 \mathrm{mg}$, for $€ 57.82$ [17]. Assuming a planned trade margin and $10 \%$ of the remaining costs allocated to production, then a production price of $6 € / \mathrm{g}$ can be deducted.

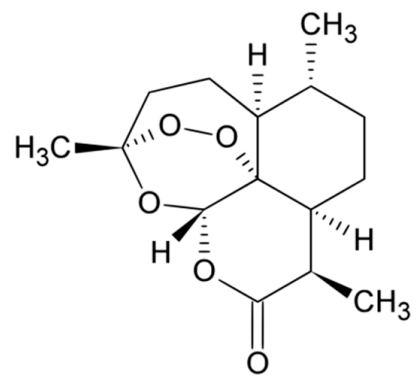

Figure 2. Structure of artemisinin.

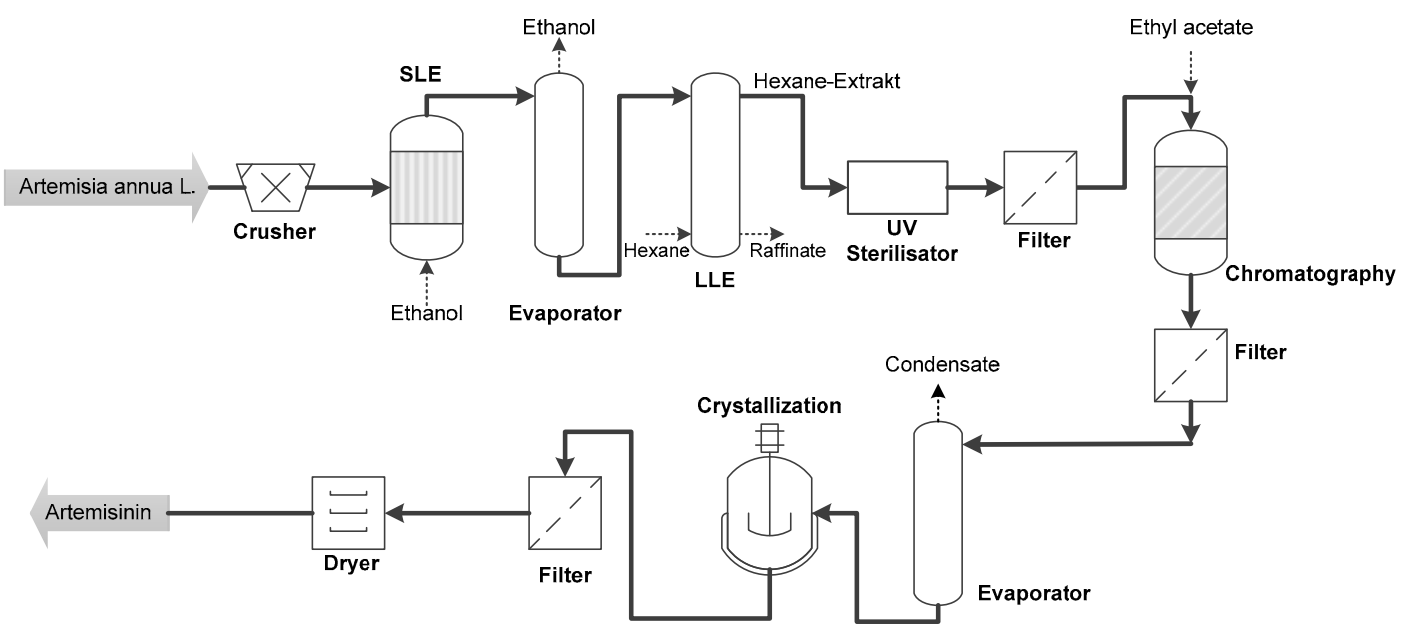

Figure 3. Flow scheme of the benchmark process, (SLE, solid-liquid extraction; UV, ultraviolet).

In addition to the shown benchmark pathway much effort was put into new, or rather enhanced, methods for the isolation of artemisinin. Lapkin et al. screened for various solvents to increase the efficiency of the solid-liquid extraction step. They applied the COSMO-RS model (short for COnductor like Screening MOdel for Real Solvents) to find potential candidates and performed an experimental validation. The screening included even non-conventional solvents in terms of solid-liquid extraction, such as fluoroform [18]. Due to the complex molecular structure of artemisinin and the characteristics of the plant material optimization of extraction is always a multi-parameter approach. In addition to physico-chemical consistent methods, design of experiments offers the possibility to search for possible points of operation and investigate the influencing parameters of the process. De O. Silva et al. showed such an approach using the Box-Behnken experimental design. As expected, the drug-solvent ratio influenced the batch extraction the most [19]. In addition to extraction and purification of artemisinin, synthesis was investigated. One promising approach is a photo-chemical continuously operated process to transform dihydroartemisinic acid into artemisinin, by Seeberger and coworkers [20,21]. The precursor dihydroartemisinic acid is extracted from annual mugwort but is found in larger quantities compared to artemisinin. Not only extraction and synthesis 
have been investigated; whole processes and value chains single unit operations in the downstream of artemisinin have been assessed [22]. Suberu et al. identified co-metabolites in the plant extract that negatively affect the crystallization of artemisinin [23]. This investigation is very important to identify those compounds that must be removed by unit operations before crystallization. Especially costly unit operations, such as chromatography, benefit from that investigation because not all substances have to be separated, but the right ones.

\section{Results and Discussion}

The process design originates from a lab-scale process development based on the complex plant extract as the feed. This data afterwards served for a scale-up to the pilot scale. The process engineering details are discussed in the parts III to IV of this study.

- In both scaling stages, the extract can be recovered by conventional solid-liquid extraction with acetone with a purity of nearly $40 \%$ and a concentration of $0.27 \mathrm{~g} / \mathrm{L}$. The yield is considered $100 \%$ in this process step. Details on solid-liquid extraction can be found in [7].

- Evaporation of the extract by means of distillation results in a concentration of about $2.5 \mathrm{~g} / \mathrm{L}$ due to the volume reduction. The yield loss amounts to about $2 \%$ for this process step.

- In the first step of purification, chlorophyll is separated by precipitation and filtration. It can be seen that the purity in the laboratory process increases to $52 \%$, in the pilot process, however, only to about $42 \%$. Due to the addition of water, the concentration drops. The yield loss in this process step is about $6 \%$ on a laboratory scale, whereas, in the pilot process, practically no yield loss is recorded. The purification effect of precipitation is overestimated by the laboratory study, yet higher yields result due to larger pilot scale quantities. Despite the low level of purification, this process step is necessary because the extract containing pure acetone would not form a miscibility gap with the solvents used in the subsequent liquid-liquid extraction.

- In the first liquid-liquid extraction, the concentration in laboratory scale greatly increases from $1.4 \mathrm{~g} / \mathrm{L}$ to about $4.8 \mathrm{~g} / \mathrm{L}$ due to the small solvent ratio ( $+340 \%$ increase). The lower solvent ratio in the pilot process results in a concentration of only about $3.7 \mathrm{~g} / \mathrm{L}$ (increase $+264 \%$ ). The concentration is therefore $30 \%$ lower in the pilot study. Similarly, at $70 \%$, the purity is higher by 20 percentage points compared to the pilot scale. In a one-step operation of the first liquid-liquid extraction on a laboratory scale, the yield drops to $80 \%$ (shown as a dot in the diagram). However, a multi-step process is assumed, resulting in an overall yield of about $87 \%$. The pilot process results in a measured yield of $90 \%$ after this process step.

- Product purity increases to $90 \%$ in both process variants in the second liquid-liquid extraction with sodium carbonate solution. This corresponds to an increase of $+140 \%$ in the laboratory and $+186 \%$ on a pilot scale. The concentration increases again by the re-extraction of the acetone from the respective organic phase into the aqueous sodium carbonate; on a laboratory scale from about $4.8 \mathrm{~g} / \mathrm{L}$ to $6.6 \mathrm{~g} / \mathrm{L}(+137 \%)$ and on a pilot scale from $3.7 \mathrm{~g} / \mathrm{L}$ to $8.4 \mathrm{~g} / \mathrm{L}(+227 \%)$. In the laboratory process, the overall yield after this step drops to about $80 \%$, whereas this process step at the pilot scale shows no measurable yield loss.

- In the subsequent chromatography (here for better comparability batch chromatography), a purity of over $99 \%$ is achieved in both processes. The pilot scale yield is $85 \%$ after this step, $77 \%$ on a laboratory scale. The concentration decreases in both processes due to the dilution in the respective eluent.

- The final crystallization and drying results in a purity of almost $100 \%$. The overall process yield after these steps is $83 \%$ in the pilot and $72 \%$ in the laboratory scale.

For the basic operations of the selected lab study with complex feed, the small error bars, as seen in Figure 4, are striking. Thus, the method to select individual process steps based on the characterization of real feed mixture can be considered robust and reproducible. In general, however, the laboratory study shows a higher loss due to a mostly one-step mode of operation and 
smaller quantities. The laboratory process has a yield of $72 \%$, the pilot process of $83 \%$ and is, thus, $15 \%$ higher. The patent-based reference process has a $59 \%$ yield. The two newly developed processes are significantly above this value ( $+40 \%$ pilot, $+22 \%$ laboratory). According to literature, the yields of common methods are between $45 \%$ and $80 \%$ [24].

With the help of these parameters, the three processes in the following chapter are subjected to a profitability analysis.

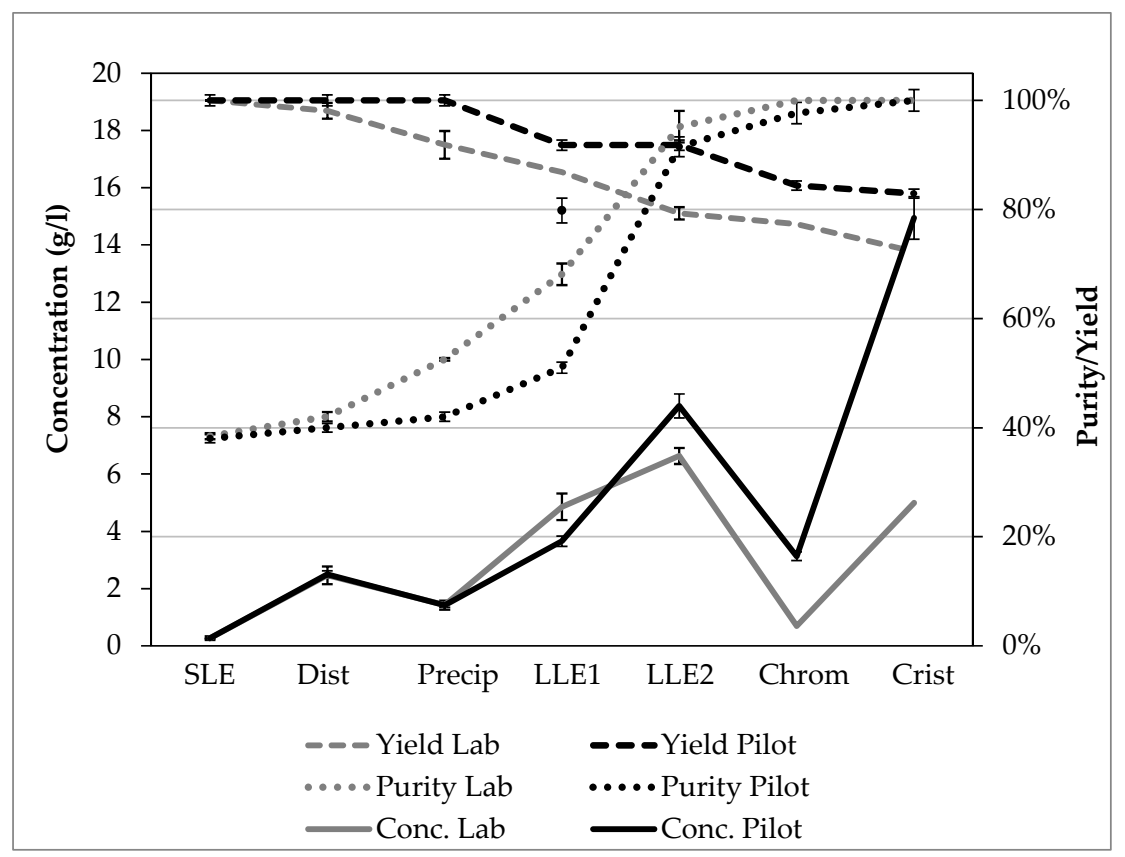

Figure 4. Overview of the process design (Conc., concentration).

\section{Economic Feasibility Study}

In the following section, the newly designed laboratory and pilot processes are evaluated from an economic point of view and compared with the reference process. The reference process is assigned to class 5 cost estimation, the laboratory process is class 4 and the pilot process is class 3 . The corresponding expected accuracies are summarized in Table 1.

Table 1. Cost estimation classes (Reprinted with the permission of Christensen, P; Dysert, L.R, AACE International, Morgantown, WV, USA, 2016 [25]). Copyright (C 2016 by AACE International; all rights reserved.

\begin{tabular}{|c|c|c|c|c|}
\hline & Primary Characteristic & & Secondary Characteristic & \\
\hline \multirow{2}{*}{ Estimate Class } & $\begin{array}{l}\text { Maturity Level of Project } \\
\text { Definition Deliverables }\end{array}$ & End Usage & Methodology & $\begin{array}{l}\text { Expected Accuracy } \\
\text { Range }\end{array}$ \\
\hline & $\begin{array}{l}\text { Expressed as \% of } \\
\text { Complete Definition }\end{array}$ & $\begin{array}{l}\text { Typical Purpose of } \\
\text { Estimate }\end{array}$ & Typical Estimating Method & $\begin{array}{l}\text { Typical Variation in } \\
\text { Low and High Ranges }\end{array}$ \\
\hline Class 5 & $0 \%$ to $2 \%$ & Concept screening & $\begin{array}{c}\text { Capacity factored, } \\
\text { parametric models, } \\
\text { judgement, or analogy }\end{array}$ & $\begin{array}{l}\mathrm{L}:-20 \% \text { to }-50 \% \\
\mathrm{H}:+30 \% \text { to }+100 \%\end{array}$ \\
\hline Class 4 & $1 \%$ to $15 \%$ & Study or feasibility & $\begin{array}{l}\text { Equipment factored or } \\
\text { parametric models }\end{array}$ & $\begin{array}{l}\text { L: }-15 \% \text { to }-30 \% \\
\text { H: }+20 \% \text { to }+50 \%\end{array}$ \\
\hline Class 3 & $10 \%$ to $40 \%$ & $\begin{array}{l}\text { Budget authorization } \\
\text { or control }\end{array}$ & $\begin{array}{l}\text { Semi-detailed unit costs with } \\
\text { assembly level line items }\end{array}$ & $\begin{array}{l}\text { L: }-10 \% \text { to }-20 \% \\
\text { H: }+10 \% \text { to }+30 \%\end{array}$ \\
\hline Class 2 & $30 \%$ to $75 \%$ & Control or bid/tender & $\begin{array}{l}\text { Detailed unit cost with } \\
\text { forced detailed take-off }\end{array}$ & $\begin{array}{l}\mathrm{L}:-5 \% \text { to }-15 \% \\
\mathrm{H}:+5 \% \text { to }+20 \%\end{array}$ \\
\hline Class 1 & $65 \%$ to $100 \%$ & $\begin{array}{l}\text { Check estimate or } \\
\text { bid/tender }\end{array}$ & $\begin{array}{l}\text { Detailed unit cost with } \\
\text { detailed take-off }\end{array}$ & $\begin{array}{l}\text { L: }-3 \% \text { to }-10 \% \\
\mathrm{H}:+3 \% \text { to }+15 \%\end{array}$ \\
\hline
\end{tabular}




\subsection{Investment Costs}

To calculate the investment costs, the unit costs of the basic operations selected in the previous section are determined by their characteristic parameters [26]. Since the prices are from the year 2002, they will be converted to 2017 using the Chemical Engineering Plant Cost Index (CEPCI). The last calculation step is the Lang-factor. This includes the peripherals belonging to the basic operations such as pumps, pipes and the electrical measurement, regulation and control technology. The Lang-factor is set at 5 , as this is the typical value for the pharmaceutical industry [26]. The investment costs of each basic operation are shown in Figure 5.

- Due to the higher yield of the pilot process less mugwort needs to be extracted, the costs for the granulator and percolator are, therefore, about $60 \%$ lower than in the reference and laboratory process.

- The costs for the liquid-liquid extraction are $120 \%$ greater in the pilot process compared to the laboratory process, as the second LLE (liquid-liquid extraction) step was also realized with one column and not with a mixer-separator. In the reference process, only a liquid-liquid extraction is performed in a packed column, resulting in only $30 \%$ of the cost of the LLE compared to the pilot process.

- The evaporators are approximately equally expensive in all three variants, whereby it should be noted here that the degree of detail of the solvent recycling increases significantly from the reference to the pilot process. Similarly, the cost of the corresponding capacitors increases.

- The costs for filters were much overestimated in the reference process. The actual costs are negligible.

- The investment costs of batch chromatography in the pilot process are $360 \%$ more expensive compared to the laboratory process and about $150 \%$ more expensive than in the reference process. This high deviation from the laboratory scale to the pilot scale is achieved by purely theoretical scaling based on thin-layer chromatograms. A high error is to be expected at this point.

- Equipment costs for crystallization are also about 300\% more expensive in the pilot process than in the laboratory or reference study. The acetone/isopropanol (VWR ${ }^{\circledR}$, Darmstadt, Germany) system theoretically considered in the laboratory study has a steeper solubility curve than the ethanol/water system used in the piloting. As a result, significantly more crystallization steps must be carried out successively in the pilot process, which consequently also results in higher apparatus costs.

- Due to the higher level of detail of the pilot study, especially solvent recycling, the cost of buffer tanks is about $150 \%$ higher than in the two comparison processes.

- The cost of drying in the pilot study was only about 7\% compared to the laboratory or reference process, as it switched from a costly vacuum belt dryer to a tray dryer.

- In the pilot process, the solvent often needs to be changed by recrystallization, for example, from the wash extraction to the chromatography support. In the laboratory process, attempts were made to integrate the solvents in the subsequent process step, which was not feasible in scale-up. As a result, additional equipment costs are incurred here.

- In summary, the pilot process results in approximately $60 \%$ higher investment costs ( $€ 7.4$ million), mainly due to the more detailed interpretation of solvent recycling, recrystallization, and chromatography. 


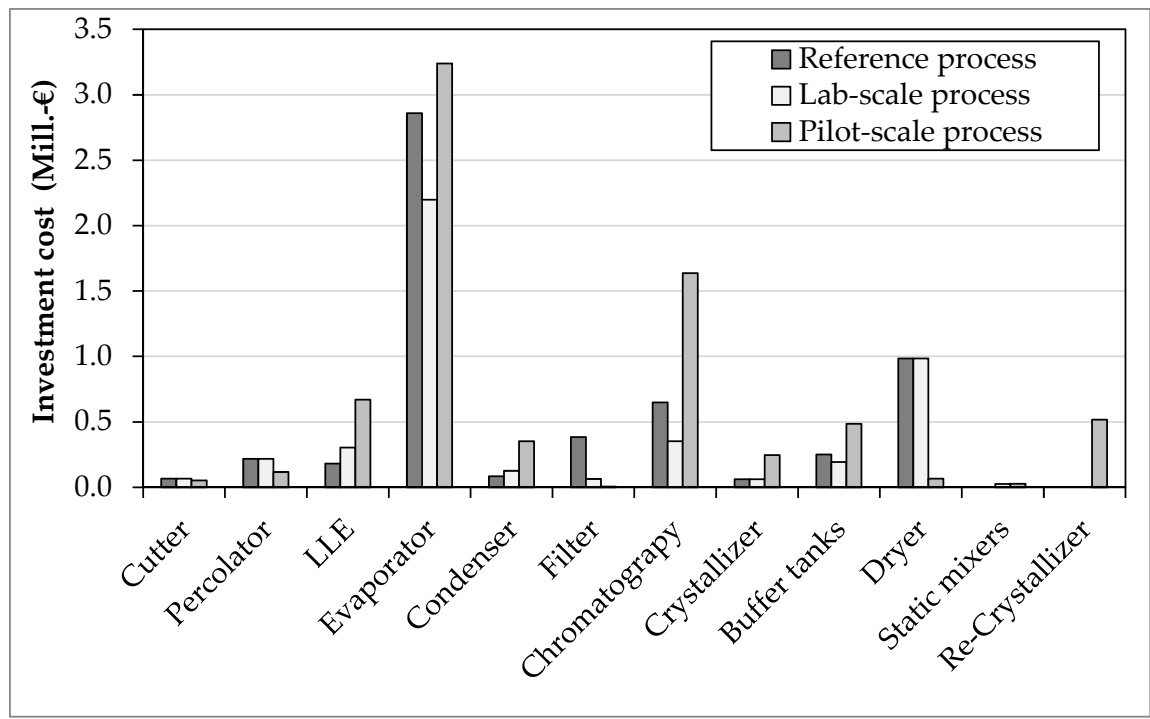

Figure 5. Summary of the investment costs.

\subsection{Operating Costs}

The annual operating costs are depicted in Figure 6.

- The process yield increases from the reference to the pilot process. This leads to the cost reduction of the plant material, which is assumed to be around $900 € / \mathrm{t}$. From the reference to the pilot process there is a savings potential of $30 \%$, from the laboratory to the pilot process of $20 \%$.

- In the laboratory process, solvent costs increase by $125 \%$ compared to the pilot process. The pilot process took a closer look at solvent recycling and reduced losses. The reference process comes with even lower costs, but this is not tenable due to the lowest level of detail. The cost of each solvent is $10 \%$ of Sigma-Aldrich listed retail prices (wholesale discount).

- In the reference and laboratory process, the service life of the adsorbent was much too short. In the pilot process, the column had a long service life, resulting in only about $6 \%$ of the cost of replacing the package.

- Total operating costs (€7.2 million) are about $25 \%$ lower in the pilot process than in the laboratory process and $15 \%$ lower than in the reference process.

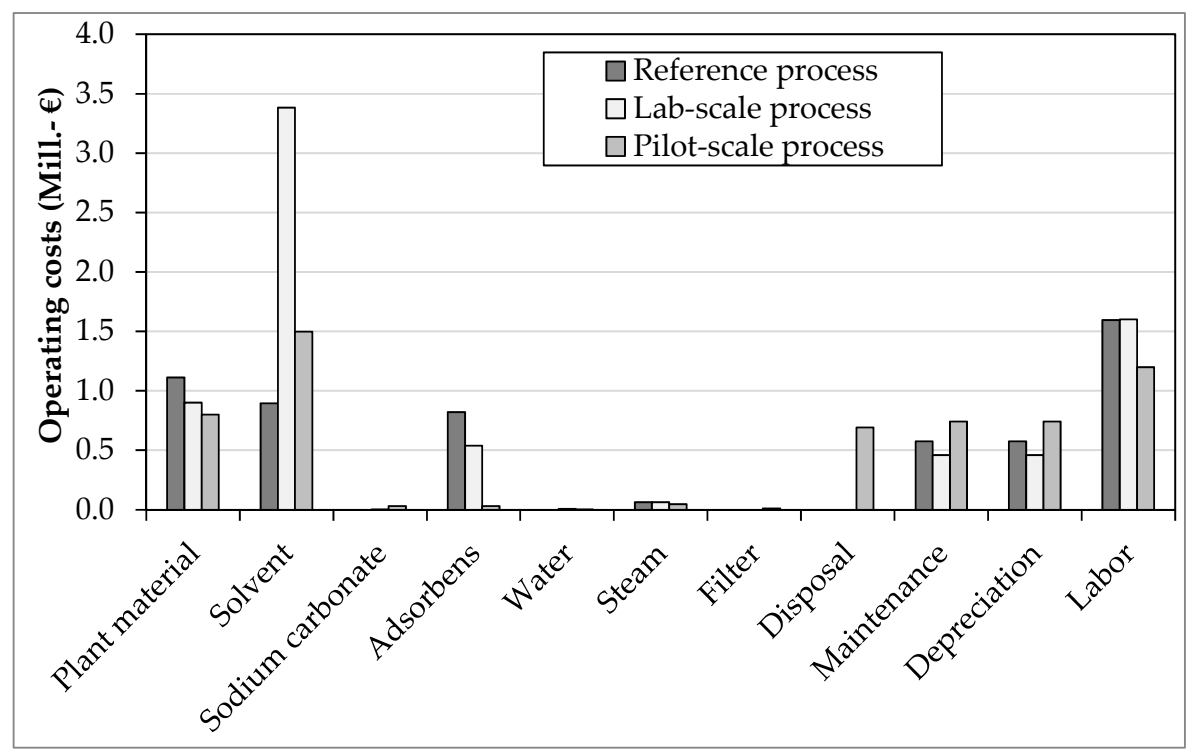

Figure 6. Summary of the operating costs. 


\subsection{Comparison and Evaluation}

- The investment costs in the reference process are 5.7 mil. $€$, in the laboratory process 4.6 mil. $€$ and in the pilot process $€ 7.4$ million. The main reason for the cost increase is the higher level of detail, in particular the basic operations used for solvent recycling and the chromatography based on measured values.

- The operating costs amount to 8.4 mil. $€$ in the reference process, to $€ 9.4$ million in the laboratory process and 7.2 Mil. $€$ during the pilot process. The costs are, therefore, the lowest in the piloting stage, which is mainly due to closed solvent circuits.

Based on the various cost studies, the manufacturing costs per gram of artemisinin are shown in Figure 7. The error bars reflect the accuracy of the cost estimate as shown in Table 1. In a direct comparison, the similar magnitudes of an average of $2.87 € / \mathrm{g}$ in the reference process, $3.21 € / \mathrm{g}$ in the laboratory process and $2.46 € / \mathrm{g}$ in the pilot process are apparent. On the one hand, this speaks for the high quality of the Class 5 cost estimate of the reference process, and on the other hand, the path from process development in the laboratory to piloting is confirmed. For better comparability, the process variant was analyzed with batch chromatography in the pilot process. With the chromatograph-free variant and production without generating profit, the production price can be reduced to $0.96 € / g$. Since malaria occurs mainly in Third World countries, the selling price must be below $0.24 € / \mathrm{g}$ [24], correspondingly higher in developed countries. To achieve this goal, the manufacturers of non-governmental organizations are supported by donations [27].

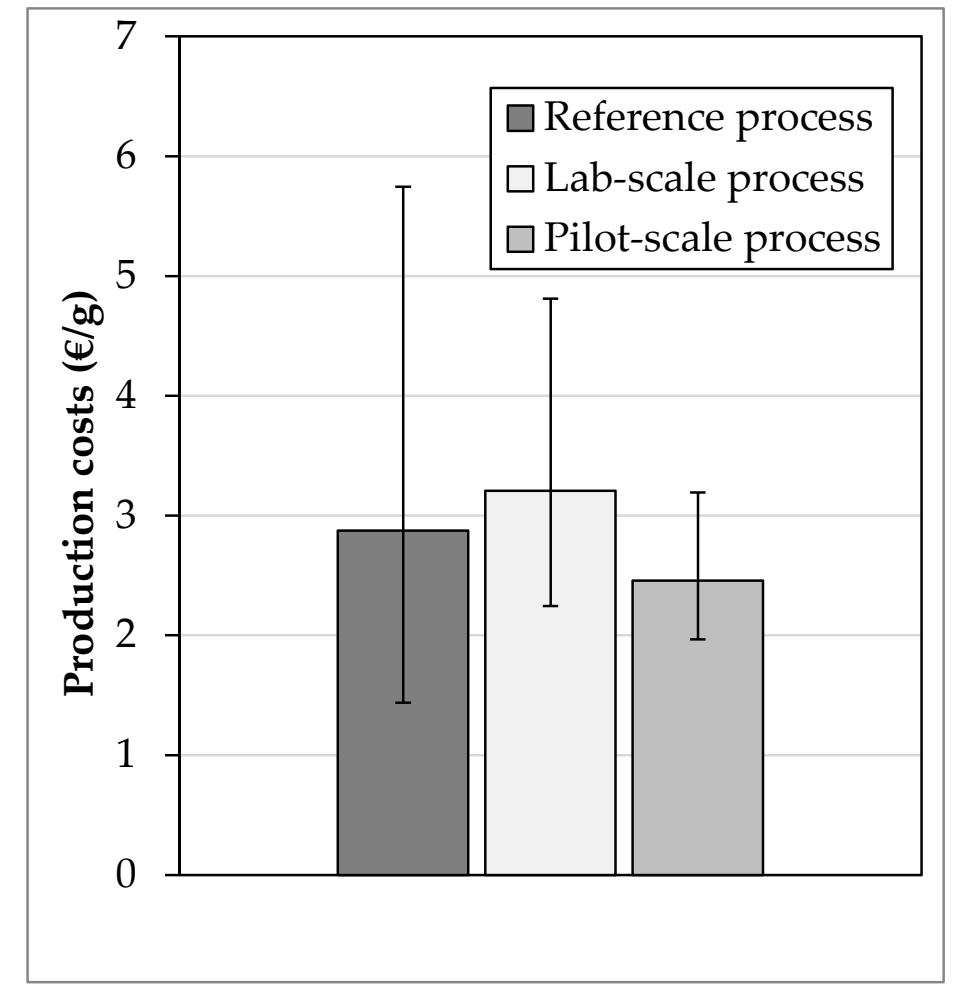

Figure 7. Summary of the specific production costs.

\section{Conclusions}

The presented study is based on a transfer of a lab-scale process to pilot-scale for the extraction and purification of artemisinin from annual mugwort. All unit operations are discussed in the related articles. The cost estimation revealed that the data from lab-scale gave a good hint towards a possible investment decision for a commercial process. The precision of data was further enhanced by piloting. 
To our knowledge no equivalent process design was ever performed by academia, revealing great potential of fully-integrated pilot-plant devices in engineering departments.

Author Contributions: M.S. conceived and designed the solid-liquid extraction experiments and conducted the cost estimation study as well as wrote the paper. A.S. designed the liquid-liquid extraction experiments and contributed to the cost estimation study. F.M. designed the chromatographic separation experiments and contributed to the cost estimation study. M.J.H. designed the crystallization experiments and contributed to the cost estimation study. L.U. contributed to the cost estimation study as well as writing and revision of the paper. J.S. substantively revised the work, contributed the materials and is responsible for conception and supervision.

Funding: The authors want to thank the Bundesministerium für Wirtschaft und Energie (BMWi), especially M. Gahr (Projektträger FZ Jülich), for funding this scientific work. We also acknowledge the financial support obtained from the Deutsche Forschungsgemeinschaft (DFG) in Bonn, Germany (project Str 586/4-2).

Acknowledgments: We gratefully acknowledge the support of the ITVP lab-team. Special thanks are also addressed to J.S., H.S., A.M., S.W., and T.W. for excellent laboratory work and fruitful discussions.

Conflicts of Interest: The authors declare no conflict of interest.

\section{References}

1. Kaßing, M.; Jenelten, U.; Schenk, J.; Hänsch, R.; Strube, J. Combination of rigorous and statistical modeling for process development of plant-based extractions based on mass balances and biological aspects. Chem. Eng. Technol. 2012, 35, 109-132. [CrossRef]

2. Ditz, R.; Gerard, D.; Hagels, H.; Igl, N.; Schäffler, M.; Schulz, H.; Stürtz, M.; Tegtmeier, M.; Treutwein, J.; Strube, J.; et al. Phytoextracts. Proposal towards a New Comprehensive Research Focus; DECHEMA Gesellschaft für Chemische Technik und Biotechnologie e.V.: Frankfurt, Germany, 2017.

3. Both, S. Systematische Verfahrensentwicklung für Pflanzlich Basierte Produkte im Regulatorischen Umfeld; Shaker: Aachen, Germany, 2015.

4. Koudous, I. Stoffdatenbasierte Verfahrensentwicklung zur Isolierung von Wertstoffen aus Pflanzenextrakten, 1. Auflage; Shaker: Herzogenrath, Germany, 2017.

5. Koudous, I.; Both, S.; Gudi, G.; Schulz, H.; Strube, J. Process design based on physicochemical properties for the example of obtaining valuable products from plant-based extracts. Int. J. Plant Sci. 2014, 17, $218-231$. [CrossRef]

6. Sixt, M.; Koudous, I.; Strube, J. Process design for integration of extraction, purification and formulation with alternative solvent concepts. C. R. Chim. 2016, 19, 733-748. [CrossRef]

7. Sixt, M.; Strube, J. Systematic and model-assisted evaluation of solvent based- or pressurized hot water extraction for the extraction of Artemisinin from Artemisia annua L. Processes 2017, 5, 86. [CrossRef]

8. Christen, P.; Veuthey, J.-L. New trends in extraction, identification and quantification of Artemisinin and its derivatives. Curr. Med. Chem. 2001, 8, 1827-1839. [CrossRef] [PubMed]

9. Krishna, S.; Bustamante, L.; Haynes, R.K.; Staines, H.M. Artemisinins: Their growing importance in medicine. Trends Pharmacol. Sci. 2008, 29, 520-527. [CrossRef] [PubMed]

10. Tu, Y. From Artemisia annua L. to Artemisinins. The Discovery and Development of Artemisinins and Antimalarial Agents; Elsevier Science: San Diego, CA, USA, 2017.

11. Liu, C.-Z.; Zhou, H.-Y.; Zhao, Y. An effective method for fast determination of artemisinin in Artemisia annua L. by high performance liquid chromatography with evaporative light scattering detection. Anal. Chim. Acta 2007, 581, 298-302. [CrossRef] [PubMed]

12. Duke, M.V.; Paul, R.N.; Elsohly, H.N.; Sturtz, G.; Duke, S.O. Localization of Artemisinin and Artemisitene in foliar tissues of glanded and glandless biotypes of Artemisia annua L. Int. J. Plant Sci. 1994, 155, 365-372. [CrossRef]

13. Nobel Foundation. The Nobel Prize in Physiology or Medicine 2015; Press Release: Stockholm, Sweden, 2015.

14. Brown, G. Artemisinin and a new generation of antimalarial drugs. Educ. Chem. 2006, 43, 97-99.

15. ElFeraly, F.S.; Elsohly, H.N. Method for the Isolation of Artemisinin from Artemisa annua. U.S. Patent 4,952,603, 28 August 1990.

16. Kumar, S.; Gupta Kumar, S.; Singh, D. Process for Isolating Artemisinin from Artemisia annua. U.S. Patent 6,685,972, 3 March 2004. 
17. DocMorris. Euratesim $320 \mathrm{mg} / 40 \mathrm{mg}$ Filmtabletten. Available online: https://www.docmorris.de/ eurartesim-320-mg40-mg-filmtabletten/08404949?wt_mc=psm.psm_cpc.medizinfuchs.default.\&erid= 1507286926572768301 (accessed on 5 September 2018).

18. Lapkin, A.A.; Peters, M.; Greiner, L.; Chemat, S.; Leonhard, K.; Liauw, M.A.; Leitner, W. Screening of new solvents for artemisininextraction process using ab initio methodology. Green Chem. 2010, 12, $241-251$. [CrossRef]

19. Silva, E.D.O.; Borges, L.L.; da Conceição, E.C.; Bara, M.T.F. Box-Behnken experimental design for extraction of artemisinin from Artemisia annua and validation of the assay method. Rev. Bras. Farmacogn. 2017, 27, 519-524. [CrossRef]

20. Lévesque, F.; Seeberger, P.H. Continuous-flow synthesis of the anti-malaria drug artemisinin. Angew. Chem. Int. Ed. Engl. 2012, 51, 1706-1709. [CrossRef] [PubMed]

21. Triemer, S.; Gilmore, K.; Vu, G.T.; Seeberger, P.H.; Seidel-Morgenstern, A. Literally green chemical synthesis of Artemisinin from PLant extracts. Angew. Chem. Int. Ed. Engl. 2018, 57, 5525-5528. [CrossRef] [PubMed]

22. Jolliffe, H.G.; Gerogiorgis, D.I. Plantwide design and economic evaluation of two Continuous Pharmaceutical Manufacturing (CPM) cases: Ibuprofen and artemisinin. Comput. Chem. Eng. 2016, 91, 269-288. [CrossRef]

23. Suberu, J.O.; Yamin, P.; Leonhard, K.; Song, L.; Chemat, S.; Sullivan, N.; Barker, G.; Lapkin, A.A. The effect of $O$-methylated flavonoids and other co-metabolites on the crystallization and purification of artemisinin. J. Biotechnol. 2014, 171, 25-33. [CrossRef] [PubMed]

24. Pilloy, J. Artemisinin market quantities and pricing. In Proceedings of the Artemisinin Conference 2010, Antananarivo, Madagascar, 12-14 October 2010.

25. Christensen, P.; Dysert, L.R. Cost Estimate Classification System: As Applied in Engineering, Procurement, and Construction for the Process Industries; AACE: Morgantown, WV, USA, 2016.

26. Peters, M.S.; Timmerhaus, K.D.; West, R.E. Plant Design and Economics for Chemical Engineers, 5th ed.; McGraw-Hill: New York, NY, USA, 2003.

27. TheGlobalFund. Global Artemisinin Manufacturers Consultation. In Proceedings of the Chengdu Meeting, Chengdu, China, 5-7 September 2016.

(C) 2018 by the authors. Licensee MDPI, Basel, Switzerland. This article is an open access article distributed under the terms and conditions of the Creative Commons Attribution (CC BY) license (http:/ / creativecommons.org/licenses/by/4.0/). 